\title{
Green synthesis and Characterization of Silver Nanoparticles using Extract of Palm Tree Bark, Palm leaf and Ghaf leaf
}

\author{
DINESH CHAND* \\ Department of Chemistry, Amity University Dubai Campus, Dubai International Academic City, \\ P. O. BOX-345019, United Arab Emerates. \\ *Corresponding author E-mail: libradinu@gmail.com \\ http://dx.doi.org/10.13005/ojc/350206
}

(Received: February 01, 2019; Accepted: March 27, 2019)

\begin{abstract}
Current study shows simple and easy method for the synthesis of silver nanoparticles using Palm bark, Palm leaf and Ghaf leaf aqueous extract. Each extracted solution used as reducing and capping agent. Various techniques used to characterize synthesized nanoparticles are DLS, FTIR and UV-Visible spectroscopy which showed absorbance peak in range of $300-800 \mathrm{~nm}$. Results confirm this green method as simple, rapid, eco-friendly, non-toxic, one step and an alternative to conventional physical and chemical methods. The silver nanoparticles were prepared from silver ions at room temperature, without using any hazardous chemical.
\end{abstract}

Keywords: Green synthesis, Silver nanoparticle, Plant extract, DLS, FTIR, UV-Visible.

\section{INTRODUCTION}

Greener approach and techniques were used for the synthesis of nanoparticles to overcome problems related to environment ${ }^{1}$. Silver nanomaterial is one of the most commercial nanomaterial with five hundred tons of silver nanoparticles production per year and is increasing year by year. Silver nanoparticles plays a major role in many fields such as catalysis, biosensors, high sensitivity biomolecular detection, medicine and anti-microbes studies which is noted to have strong inhibitory and bactericidal effects along with the anti-inflammatory, anti-angiogenesis and anti-fungal activities. ${ }^{2,3}$
Scores of techniques are available for silver nanoparticles synthesis like chemical reduction, sol gel, ion sputtering, etc. ${ }^{4-7}$ Many of them includes the use of hazardous chemicals or high energy requirements, which are very difficult to carry out with wasteful purifications. Currently, the chemical methods widely used for nanoparticles synthesis were associated chemical precursor contamination, solvent toxicity, and hazardous by product formation. Hence, it is necessary to find new synthesis route which would be cheap and environment friendly. Over the decades various plant resources were successfully utilized for synthesis of metal nanoparticles. These plants are rich resources of phytochemicals with aromatic hydroxyl, aldehyde

This is an Open Access article licensed under a Creative Commons license: Attribution 4.0 International (CC- BY). Published by Oriental Scientific Publishing Company @ 2018

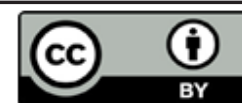


and carboxylic functional groups. Out of various nanoparticles used in the pharmaceutical industry, silver nanoparticles are one of the important materials in nanomedicine. It has been found that techniques using naturally occurring reagents such as biodegradable polymers (Chitosan), microorganisms (like bacteria, fungi, etc.), plant extracts and sugars as reductants and capping agents attracts many researchers. ${ }^{8-10}$ Green synthesis of nanoparticles also provides many advances over other methods as they are simple, cost-effective, one-step and environment friendly and often results in more stable materials. Microorganisms can also be used to produce nanoparticles but the rate of synthesis is slow compare to routes including plants mediated synthesis. ${ }^{11,12}$ Many researchers used plant (flower/leaf/root etc.) extract for the synthesis of nanoparticles with high antibacterial activities and size ranging from 5 to $20 \mathrm{~nm} \cdot{ }^{13-16}$

A greener and safe method used in this study instead of conventional method for the synthesis of silver nanoparticles. A palm tree (Arecaceae family) and ghaf tree (Fabaceae family) were used for the synthesis of silver nanoparticles. These plants are commonly available in United Arab Emirates (UAE). Palm and Ghaf tree have been important to humans as many common products and foods are derived from them. They are used for many commercial and medicinal purposes. The aqueous extract of the leaf and bark contains phytochemicals such as amino acids, alkaloids, carbohydrates, flavonoids, glycosides, steroids, and tannins. Due to the presence of these biogenic multifunctional molecules, silver nanoparticles were synthesized by using extract solution of palm leaves, ghaf leaves and palm bark without using any additional harmful chemicals. Characterization of the synthesized nanoparticles done by using UV-visible spectrophotometer, dynamic light scattering (DLS) and Fourier transform infrared spectroscopy (FT-IR). The method applied here in current study is simple, non-hazardous and sustainable.

\section{MATERIALS AND METHODS}

Silver nitrate used for current study was purchased from Merck, Germany and of $99 \%$ purity. The synthesis of plant extract based nanoparticles was carried at room temperature.

\section{Preparation of plant extract}

Palm bark, Palm leaves and Ghaf leaves was used for the preparation of silver nanoparticles on the basis of their availability, low cost and vast medicinal properties. Fresh leaves and bark were collected in month of October. Firstly, leaves and bark were washed with running tap water to remove debris and other contaminated organic contents and then with de-ionized water. Cleansed leaves and bark were air dried at room temperature. Palm leaves were cut into small pieces of around 1 to $2 \mathrm{~cm}$ in length, Palm bark were crashed into very small pieces while ghaf leaves were just separated from the branch since they are already small. Approximately $20-22 \mathrm{~g}$ of plant sample (leaf and bark) were used and transferred to a beaker having $100 \mathrm{ml}$ of de-ionized water. The content boiled for $30 \mathrm{~min}$ to get plant extract. The extract was cooled down and filtered and kept at $4^{\circ} \mathrm{C}$ for further analysis. Fig. 1 shows plant extract for each sample.

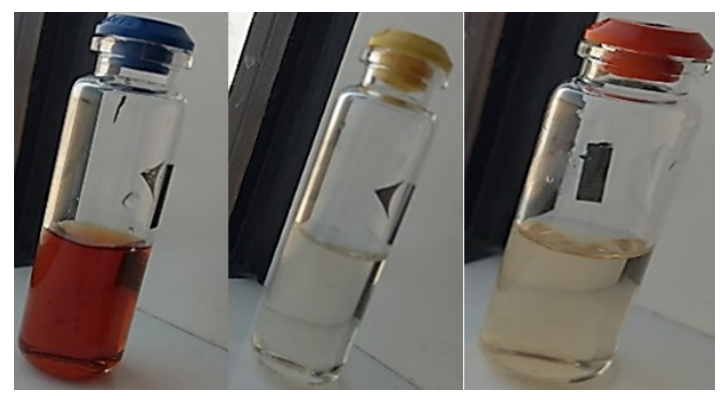

Fig. 1. Initial colour (a) Palm bark extract (b) Palme leaves extract and (c) Ghaf leaves extract

\section{Synthesis of silver nanoparticles}

$1 \mathrm{mM}$ solution of silver nitrate was prepared and kept in dark amber bottle to prevent its precipitation. For the preparation of nanoparticles, $2 \mathrm{~mL}$ of each extract sample were mixed with $10 \mathrm{~mL}$ of $1 \mathrm{mM} \mathrm{AgNO}_{3}$ solution in three bottles with different cap color: Palm Bark extract- $\mathrm{AgNO}_{3}$ with orange bottle cap, Palm leaves extract- $\mathrm{AgNO}_{3}$ with yellow bottle cap and Ghaf leaves extract- $\mathrm{AgNO}_{3}$ with blue bottle cap as shown in the Fig. 1. The bottles kept at room temperature without stirring and the change in colour were recorded in an interval of every 30 minutes. It has been found that the final color for palm bark extract- $\mathrm{AgNO}_{3}$ (orange cap) is dark brown, palm leaves extract- $\mathrm{AgNO}_{3}$ (yellow cap) is dark orange and Ghaf leaves extract- $\mathrm{AgNO}_{3}$ (blue cap) is dark red. The final change in colour were recorded and shown in Figure 2. 


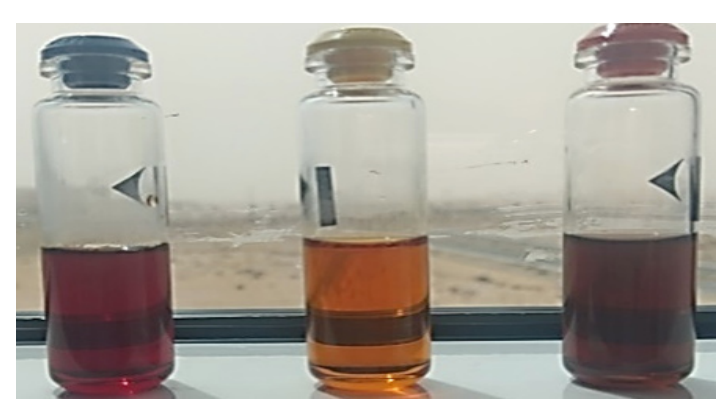

Fig. 2. Final Colour of plant extract silver nanoparticles

\section{RESULTS AND DISCUSSION}

In this study, Silver nanoparticles (AgNPs) were prepared by using plant extract where reductant from plant extract directly reduced $\mathrm{Ag}^{+}$to $\mathrm{Ag}$ atoms $\left(\mathrm{Ag}^{\circ}\right)$. During the synthesis process, the solution of $\mathrm{AgNO}_{3}$ and plant extract shows colour change from light yellow $\rightarrow$ orange $\rightarrow$ brown $\rightarrow$ dark brown (palm bark extract), light orange $\rightarrow$ orange $\rightarrow$ dark orange (palm leaves extract) and: light red $\rightarrow$ red $\rightarrow$ dark red (Ghaf leaves extract). The change in colour for all the solutions indicates the reaction between plant extract and silver nitrate solution.

The hydrodynamic diameter (particle size) of the synthesized nanoparticles was determined by using DLS. The Palm bark extract based nanoparticles shows best result with $32.2 \mathrm{~nm}$ particle size compared to other two extracts solution NPs. Fig. 3 shows size of nanoparticles for Palm leaves (119.1 nm), Bark extract (32.2 nm) and Ghaf leaves $(87.0 \mathrm{~nm})$ based nanoparticles. It was observed that samples without stirring at room temperature had the smaller nanoparticle size.

The optical properties of AgNps were explained by UV-Vis absorption spectroscopy, an important and most commonly used technique, to ascertain the formation of metal nanoparticles. The UV analysis was done for all the three extract based silver nanoparticles and tabulated in Table 1. Fig. 4 clearly showed UV spectra of plasmon resonance band observed at 430-470 nm for all AgNPs similar to those reported in literature. ${ }^{17}$ The spectrum also reveals few weak absorption bands due to the presence of organic compounds (from plant extract) that can interact to reduce the silver ions.

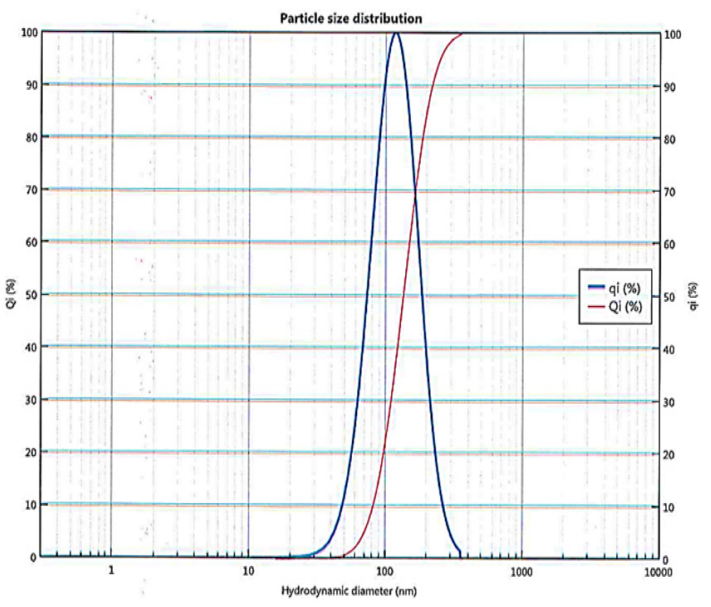

Fig. 3 (a). DLS analysis of Palm leaves extract based silver nanoparticles

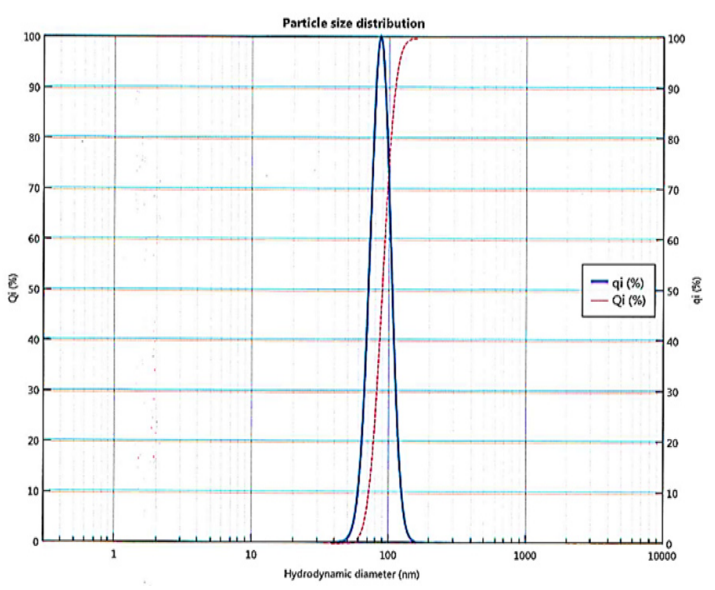

Fig. 3 (b). DLS analysis of Ghaf leaves extract based silver nanoparticles

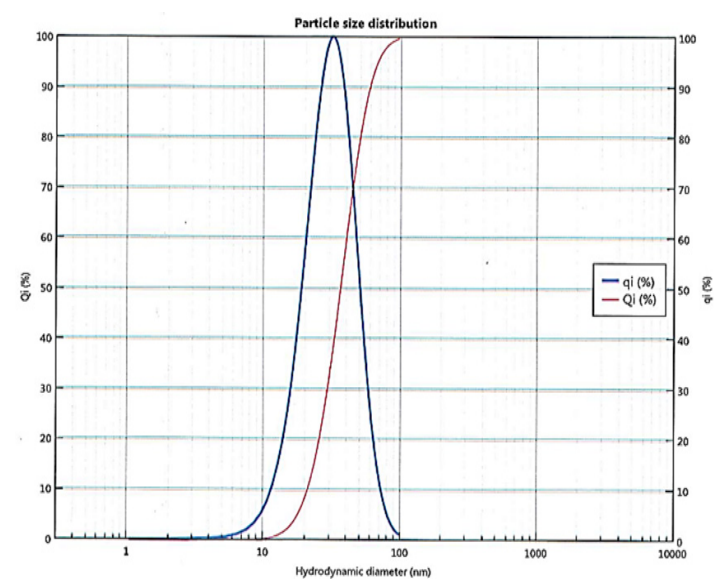

Fig. 3 (c). DLS analysis of Palm bark extract based silver nanoparticles 


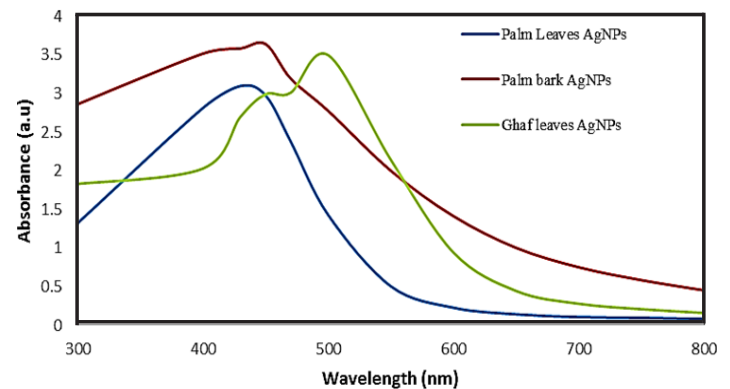

Fig. 4. UV-Visible spectrum of AgNPs using different plant extracts

Table 1: UV-VIS analysis for silver nanoparticles at room temperature

\begin{tabular}{lccc}
\hline \multicolumn{3}{c}{ Absorbance (a.u) } \\
\hline $\begin{array}{l}\text { Wavelength } \\
\lambda(\mathrm{nm})\end{array}$ & $\begin{array}{c}\text { Palm leave } \\
\text { AgNPs }\end{array}$ & $\begin{array}{c}\text { Palm Bark } \\
\text { AgNPs }\end{array}$ & $\begin{array}{c}\text { Ghaf leave } \\
\text { AgNPs }\end{array}$ \\
\hline 300 & 1.319 & 2.858 & 1.825 \\
400 & 2.808 & 3.512 & 2.024 \\
430 & 3.092 & 3.578 & 2.695 \\
450 & 2.969 & 3.634 & 2.985 \\
470 & 2.374 & 3.188 & 3.005 \\
500 & 1.421 & 2.769 & 3.491 \\
550 & 0.500 & 1.995 & 2.136 \\
600 & 0.223 & 1.407 & 0.936 \\
650 & 0.138 & 0.998 & 0.439 \\
700 & 0.102 & 0.746 & 0.274 \\
750 & 0.092 & 0.580 & 0.204 \\
800 & 0.077 & 0.447 & 0.155 \\
\hline
\end{tabular}

The molecular vibrations lead to the specific bands were obtained using IR spectroscopy. The results of the FTIR analysis of best plant extract silver nanoparticle shown peak in the range of 500$4000 \mathrm{~cm}^{-1}$ (Fig 5). The dual role of the plant extract as a reducing and capping agent and presence of some functional groups was confirmed by FTIR analysis of silver nanoparticle. A broad band obtained around $3338.98 \mathrm{~cm}^{-1}$ for Palm bark Ag-NPs corresponds to $\mathrm{N}-\mathrm{H}$ stretching vibration of group $\mathrm{NH}_{2}$ and $\mathrm{OH}$ stretching of water. Another small peak at $1634.53 \mathrm{~cm}^{-1}$ indicates presence of double bond in a nanoparticles which probably due to $\mathrm{C}=\mathrm{O}$ group or amide stretching. It means conjugation moves absorptions to lower wave numbers. The broadening of peak/band indicates the formation of nanoparticles due to reduction. The observed peaks are mainly attributed to flavanoids and terpenoids excessively present in plants extract. FTIR spectrum for other two nanoparticles was not so clear, hence not included for discussion. Only bark based nanoparticles gave good and best results. The results are in good agreement with those found in literature. ${ }^{18}$

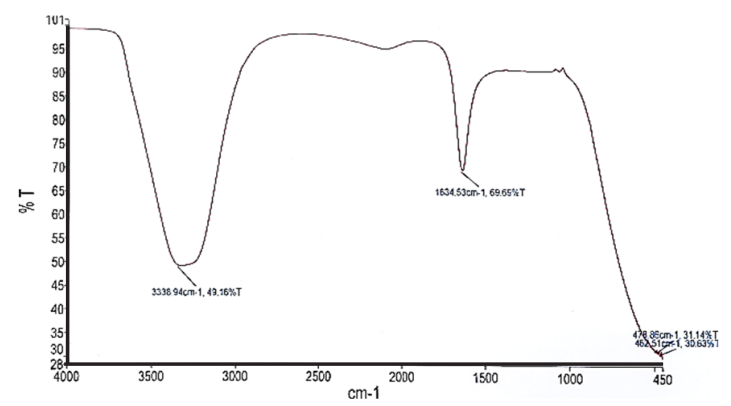

Fig. 5. FTIR spectrum of palm bark - AgNPs

\section{CONCLUSION}

A simpler and easy method for the synthesis of AgNP's using plant extracts (palm bark, palm leaf and ghaf leaf) were reported in this study. Based on the method used, we conclude that using plant extract for the synthesis of nanoparticles useful and beneficial in many ways like it is energy efficient, cost effective and leading to lesser waste to keep environment safe for human health. Therefore, method reported in this study satisfies all the conditions of a $100 \%$ green chemical process. This greener method will be an alternative to the conventional physical and chemical methods used for synthesis of silver nanoparticles and play an important role in the field of biomedical research, opto-electronics and medical devices in near future.

\section{ACKNOWLEDGEMENT}

The author sincerely thanks $\operatorname{Dr} \mathrm{N}$. Ramachandaran Provice Chacellor, Amity University Dubai for their encouragement and support.

\section{REFERENCES}

1. Thuesombat, P.; Hannongbua, S.; Akasit, S.; Chadchawan, S. Ecotoxicol Environ Saf., 2014, 104, 302-309.
2. Larue, C.; Castillo, H.; Sobanska, S.; Cécillon, L.; Bureau, S.; Barthès, V.; Ouerdane, L.; Carrière, M.; Sarret, G. J. Hazards Mater., 2014, 264, 98-106. 
3. El-Chaghaby, G.A.; Ahmad, A.F. Orient. J. Chem., 2011, 27, 929-936.

4. Bindhu, M.R.; Umadevi, M. Spectrochim. Acta A., 2015, 135, 373-378.

5. Mahdi, S.; Taghdiri, M.; Makari, V.; RahimiNasrabadi, M. Spectrochim. Acta A., 2015, 136, 1249-1254.

6. Padalia, H.; Moteriya, P.; Chanda, S. Arab. J. Chem., 2015, 8(5), 732-741.

7. Sre, P.R.R.; Reka, M.; Poovazhagi, R.; Kumar, M.A.; Murugesan, K. Spectrochim. Acta A., 2015, 135, 1137-1144.

8. Ahmed, S.; Ahmad, M.; Ikram, S. J.Applicable Chem., 2014, 3(2), 493-503.

9. Ahmed, S.; Ikram, S. Int. J. Pharm. Sci. Rev. Res., 2015, 6(1), 14-30.

10. Kharissova, O.V.; Dias, H.V.R.; Kharisov, B.I.; Pérez, B.O.; Pérez, V.M. J. Trends Biotechnol., 2013, 31, 240-248.
11. Mittal, J.; Batra, A.; Singh, A.; Sharma, M.M Adv. Nat. Sci: Nanosci. Nanotechnol., 2014, 5, 10.1088/2043-6262/5/4/043002.

12. Ahmed, S.; Ahmad, M.; Swami, B.L.; Ikram, S. J. Adv. Res., 2016, 7(1), 17-28.

13. Sadeghi, B.; Gholamhoseinpoor, F. Spectrochim. Acta A., 2015, 134, 310-315.

14. Kumar, S.A.; Ravi, S.; Velmurugan, S. Spectrochim. Acta A., 2013, 115, 388-392.

15. Logeswari, P.; Silambarasan, S.; Abraham J. Sci Iran., 2013, 20, 1049-1054.

16. Veerasamy, R.; Xin, T.Z.; Gunasagaran,S.; Xiang, T.F.W.; Yang, E.F.C.; Jeyakumar, N. J. Saudi Chem Soc., 2011, 15, 113-120.

17. Obaid, A.Y.;Al-Thabaiti, S.A.;Al-Harbi, L.M.;Khan, Z. Adv. Res. J. Microbiol., 2015, 3(8), 119-126.

18. Mahdi, S.; Taghdiri, M.; Makari, V.; RahimiNasrabadi, M. Spectrochim. Acta A., 2015, 136, 1249-1254. 